\title{
RESISTÊNCIA E LIBERDADE NA CRÍTICA DA RAZÃO POLÍTICA DE MICHEL FOUCAULT: A FILOSOFIA COMO PRÁTICA DA PARRHESIA
}

\section{Chrlstlan Fernando Rlbelro Gulmarães Vncl ${ }^{1}$}

\begin{abstract}
RESUMO
Este artigo se dispõe a analisar a crítica da razão política elaborada pelo último Foucault, sua filiação à tradição crítica kantiana bem como seu ultrapassamento e a exigência por uma nova ética pautada em valores estéticos. Procedendo à leitura e análise de alguns textos escritos entre finais da década de 1970 e início da de 1980, buscaremos elucidar o projeto ético-estético-político foucaultiano através de seu projeto crítico, salientando a importância da análise arquegenealógica para a compreensão das artes de governo moderna e da ontologia de nós mesmos. Trazer à tona os questionamentos do filósofo francês em seus últimos escritos torna possível uma atualização do papel do pensamento filosófico: buscar a denúncia dos abusos da racionalidade ligada às práticas de poder, bem como reativar a possibilidade da liberdade nos cenários nos quais o poder atua de modo irrestrito. A busca por uma outra ética, capaz de romper com os limites do pensamento representativo, se faz necessária dentro deste cenário: recusar o que somos e nos moldar em um outro sistema de pensamento para, então, atingirmos uma real prática refletida da liberdade. Importa ainda investigar a importância do conceito de Parrhesia, aqui traduzida por dizer-verdadeiro, desenvolvida nos últimos cursos ministrados por Michel Foucault no Collège de France para se atingir a máxima potência na revolta ética preconizada pelo filósofo.
\end{abstract}

Palavras-chave: Filosofia política -Crítica da razão política- Foucault

\begin{abstract}
This paper sets out to analyze the political critique of reason established by the late Foucault, his membership of the Kantian critical tradition, as well as his transcendence, and the requirement for a new ethic based on aesthetic values. Proceeding to the reading and analysis of some texts written in the late 1970 s and early 1980s, our project will seek to elucidate the ethical-aesthetic-political Foucault through his critical project, stressing the importance of archgenealogical analysis in order to understand the modern arts of government and the ontology of ourselves. When we revive Foucault's questions on his last texts, an update is taken place in the philosophica. 1 thought: to be aware of the excesses practiced by the power's rationality, as well as to renew the practice of liberty in scenarios where power acts without restraints. The search for different ethics, capable of breaking the limits of representational thought, is

\footnotetext{
${ }^{1}$ Doutor pela Faculdade de Educação da Universidade de São Paulo (FE-USP). Integrante do grupo de pesquisa do CNPq denominado CoPERP - Coletivo de Pesquisadores sobre Educação e Relações de Poder
} 
necessary in this scenario: refuse what we are and shape into another system of thought in order to achieve a reflected, actual practice of freedom. It should also investigate the importance of the concept of parrhesia, here translated by true speech, developed in recent courses administered by Michel Foucault at the Collège de France in order to achieve maximum power in the revolted ethics advocated by the philosopher.

Keywords: Political philosophy - Critique of Political Reason - Foucault

\section{Introdução}

Em seus derradeiros escritos, Foucault esboçou um vívido interesse na elaboração de uma crítica da razão política, um projeto que poderíamos descrever como pretensioso, mas que não deixava de dialogar com certa função assumida pelo pensamento ocidental, qual seja: buscar a crítica do papel exercido pela razão nas estruturas políticas. Desde finais do século XVIII, cabia à filosofia, nos lembra Foucault (2010), a importante tarefa de vigiar os abusos de poder cometidos em nome de uma determinada racionalidade política. Uma função visando regular e problematizar a estreita aliança forjada entre filosofia e política, aliança esta que deu origem às formas de governo maquinadas organicamente em certo sistema de pensamento e possibilitando, ou fomentando, que atrocidades fossem cometidas em nome de dada razão. Em nome de uma razão que prometia a liberação do homem, por exemplo, surgiram diversas formas de governo que agiam pelo terror ou pela burocracia - ou mesmo pelo terror burocrático - e que acabaram instaurando uma prática política e moral cujos efeitos ainda podem ser sentidos. Nessa configuração, o próprio poder tem que ser colocado em questão e cabe à filosofia, retomando essa antiga função, pôr "um limite ao excesso de poder, a essa superprodução do poder, a cada vez e em todos os casos em que havia o risco de ele se tornar perigoso" (FOUCAULT, 2010a, p.38-38).

Foucault, ao buscar recuperar essa típica função da filosofia, assume retomar um projeto iniciado por Immanuel Kant que, através de seu projeto crítico, almejou estabelecer outra relação com o presente e com as práticas políticas vigentes em sua época. A filosofia kantiana exigia certa obrigação com o presente, uma espécie de compromisso em tirar o homem de sua menoridade - conforme defende o pensador alemão em O que é o esclarecimento? (KANT, 2013). Em suma, uma atitude frente ao estado das coisas e que Foucault 
compreende como uma "atitude de modernidade" (FOUCAULT, 2008, p. 338). Atitude de uma época, a Aufklärung, que deve submeter tudo à crítica, incluindo aí a própria filosofia que acabou por encerrar-se em uma atitude reflexiva/contemplativa a qual deve ser rompida. Dessa maneira, a filosofia não deve apenas se esgotar nos limites de seu próprio projeto, esclarecer os limites da razão tal qual postulado na primeira das críticas kantianas (KANT, 2011); pelo contrário, a filosofia tem de ser posta à prova, esclarecendo sua própria atividade em ato, compreendendo os filósofos como elementos e também agentes de uma dada época (KANT, 2013).

A atitude filosófica preconizada por Kant, a qual Foucault acaba por filiar-se, traz à tona a questão da relação com o presente e exige do filósofo o estabelecimento de um certo compromisso com sua contemporaneidade. Desse modo, a crítica da razão política não deve se restringir apenas a elucidação da natureza dos sistemas políticos, buscando esclarecer seus fundamentos ou legitimar os seus poderes e direitos; mas, pelo contrário, seguindo Foucault (2008), deve buscar interpelá-los em sua história e geografia, em seu passado imediato e sua atualidade, seu lugar e seu momento, para assim desmascarar os abusos cometidos cotidianamente por esses sistemas em nome de certa razão.

Explanado o quadro de filiação que possibilita esta crítica da razão política pautada numa nova atitude frente ao poder, cabe compreender seu funcionamento - mesmo sabendo que tal questão ficará longe de ser esgotada nestas parcas linhas. Primeiro, cabe entendermos o que significa interpelar a razão em sua história e geografia. Buscaremos compreender este ato através de um esboço das análises elaboradas por Foucault em finais da década de 1970, momento em que vemos a elaboração do que podemos chamar de uma arquegenealogia da razão política. Procuraremos, também, conectar essa discussão com aquela empreendida acerca do gesto parrhésico, temática explorada nas derradeiras obras do pensador francês.

\section{A arque-genealogia foucaultiana da razão política: uma crítica vitalista}

Em primeiro lugar, devemos compreender de que trata e como funciona a arque-genealogia foucaultiana da razão política? O objeto de que trata é o próprio governo, mas não no sentido tomado usualmente, ligado à razão 
estatal somente, mas num sentido amplo: da alma, da família, da conduta, da saúde, etc. Através da análise de uma vasta literatura acerca desta questão do governo, Foucault pode compreender as inúmeras artes de governar, seu surgimento e evolução histórica. Interessa ao filósofo ressaltar as inúmeras formas de governo que foram perdidas ou abandonadas, cada uma engendrando uma determinada arte - uma vez que o governo não emana do objeto, não possuí uma natureza, mas é criado à luz de certas relações.

Da análise do vasto campo sobre o qual recaía o governo, desprendemos que a arte de governar deveria dar conta de três esferas distintas: 1) a da conduta pessoal; 2) a da vida dentro de um conjunto populacional; e por fim 3) a da administração de uma dada população em dado território sob determinado sistema político. Assim, muito além de uma ciência do Estado - restrita apenas à terceira das esferas foucaultianas -, podemos resumir a ideia de governo da seguinte forma: como o fruto do casamento entre disciplinarização dos corpos e governo das almas bem como a busca da melhor forma de governar a todos e cada um ao mesmo tempo dentro de dada territorialidade política.

Ora, podemos notar que o vasto campo geográfico sobre o qual incidia as práticas de governo sofreu certo esvaziamento, sendo o conceito totalmente abarcado por uma ciência do Estado. Tal processo, por sua vez, não parece ter sido inocente, mas decorrente da elaboração de uma intricada racionalidade que foi capaz de aliar interesses particulares a um interesse maior, uma racionalidade capaz de atingir um todo e suas partes, funcionando de forma totalizadora e individualizadora ao mesmo tempo.

Através da arque-genealogia apresentada por Foucault ao longo de sua obra produzida na década de 1970, conseguimos compreender como ocorreu tal processo, a redução do campo geográfico sobre o qual recaíam as formas de governo através de uma re-configuração histórica. A razão que faz funcionar o Estado moderno, novo detentor das artes de governo, não ignorou os indivíduos e o vasto campo que era coberto por aquela ampla literatura acerca do governo, ao contrário: buscou compreendê-los e inseri-los em uma nova forma passível de governar, a população, e criando condições para submetê-los a formas de vida suscetíveis de controle (FOUCAULT, 2010b). A crítica da razão política possibilitada pela arque-genealogia foucaultiana, em certo sentido, visa 
combater não somente os abusos cometidos pelos Estados em nome de certa razão, mas também essas formas de vida criadas no interior e impostas aos indivíduos.

Para Foucault, essas formas de vida calam a força plástica do pensamento e impedem a irrupção de modos outros de agir e se portar, não conformados a valores universais ou mesmo uma moral. Nesse sentido, o pensamento foucaultiano afasta-se ou desloca a atitude de modernidade kantiana. Foucault, diferentemente de Kant, não acredita em uma esfera racional capaz de regular o campo da ação individual, uma vez que, para o filósofo francês, as respostas que podemos dar ao tempo presente são sempre contingenciais e jamais podem possuir um valor universal. Não há espaço, na crítica da razão política foucaultiana, para regras universais capazes de regular a ação individual - os ditos imperativos categóricos. Cada situação vivenciada, cada imposição de formas de vida, exige uma resposta contingencial e modos de agir únicos.

Temos em Foucault a busca por uma atitude-limite, só passível de surgimento após um longo trabalho analítico sobre a forma que nos constituímos como sujeitos, o traçado da ontologia de nós mesmos elaborado pela análise arque-genealógica, e uma ultrapassagem dos limites impostos pelo pensamento através da criação de uma nova e efêmera atitude. Atitudeexperiência, criada e colocada à prova pelo que poderíamos chamar de uma crítica prática-plástica. É na busca por esta junção do ético-estético-político que as análises empreendidas pelo filósofo apontam; uma tentativa de munir seus leitores e a si mesmo de armas capazes de permitir uma reformulação de si, a criação de novas formas de vida potencialmente políticas. Cabe nos indagarmos: como isto é possível? Como, através de uma reformulação plástica de nosso êthos, é possível alcançar efeitos políticos de longo alcance entendendo aqui as artes de governo ligadas ao Estado? Longe de buscar esgotar tal questão, propomos aqui uma rápida passagem por certos textos do chamado último Foucault que poderão nos ajudar a pensá-la e desdobrá-la. O primeiro texto que, acreditamos, pode vir a nos ajudar data de 1979 e intitula-se É inútil revoltar-se? Neste, lemos:

As revoluções pertencem à história. Mas, de certa forma, lhe escapam. O movimento com que um só homem, um grupo, uma minoria ou todo um povo diz 'não obedeço mais', e joga na cara de um poder que ele considera injusto o risco de sua vida. 
(FOUCAULT, 2010c, p.72).

Interessa-nos notar neste texto a presença desta espécie de capacidade que um grupo, ou até mesmo um indivíduo, tem em colocar na cara de um poder, considerado por aquele como injusto, o risco de sua vida. Arriscar-se contra um poder abusivo, recusando-se a obedecer e utilizando como arma sua própria vida. A existência dos indivíduos, objeto das ações individualizantes da racionalidade política moderna é moldada dentro de certos limites, as supramencionadas formas de vida, e apenas ao elaborar um trabalho crítico sobre sua condição, ao reconhecer o absurdo dos limites impostos, o indivíduo escapa da configuração que lhe é imposta e abre-se para o campo do impensável: sua existência torna-se resistência!

O indivíduo é afetado por um pensamento outro, fruto do trabalho crítico, que o leva a recusar o espaço de representação em que se situa, deste encontro seu campo de experimentação acaba por expandir-se. Este encontro com uma outra experiência do pensamento faz com que indivíduo e mundo, ambos pré-configurados por certa experiência de pensamento, se corroam e recriem-se.

Impensável que se manifesta em ato, através da tomada da palavra uma espécie de não obedeço mais! -, que rompe o caráter representacional da política e faz com que a vida deixe de ser mera massa a ser moldada nas mãos de um poder. Podemos perceber que a resistência perpassa, em um átimo, o campo do pensar, do falar e do agir; ambos se confundem em um único e mesmo acontecimento. Através de um trabalho crítico sobre si, a relação do indivíduo com seu tempo presente e seu modo de ser histórico, o indivíduo reconhece os limites impostos e julga o que "não é, ou não é mais, indispensável para a constituição de nós mesmos como sujeitos autônomos" (FOUCAULT, 2008, p.345).

A filosofia analítica do poder, que possibilita essa crítica da razão, permite ao sujeito moldar-se de uma outra forma e tensionar o campo do pensar e o do viver. Tal tensão lança-nos num empreendimento que perpassa o campo do pensamento em sua atualidade, sem intermédios de representações da vida ou do futuro daqueles que resistem. Tensão que resvala no campo social, podendo gerar uma reação em cadeia. Esse é o papel que compete à filosofia, à crítica da razão política vislumbrada por Foucault: 
Talvez a filosofia possa ainda desempenhar um papel do lado do contrapoder, com a condição de que esse papel não consista mais em impor, em face do poder, a própria lei da filosofia, com a condição de que a filosofia deixe de se pensar como profecia, com a condição de que a filosofia deixe de se pensar como pedagogia, ou como legislação, e que ela se dê por tarefa analisar, elucidar, tornar visível, e, portanto, intensificar as lutas que se desenrolam em torno do poder, as estratégias dos adversários no interior das relações de poder, as táticas utilizadas, os focos de resistência, em suma, com a condição de que a filosofia deixe de colocar a questão do poder em termos de bem ou de mal, mas sim em termos de existência.(FOUCAULT, 2010a, p.43).

A filosofia não deve impor, anunciar ou ensinar sua própria razão, ela é um sutil e laborioso pensar sobre o poder em termos de existência, um tornar visível justamente o que é visível e, por isso mesmo, não o percebemos. Tratase de perceber que não se escapa das relações de poder de um só golpe, de forma maciça, mas que elas funcionam cotidianamente e necessitam ser apreendidas em sua microfísica.

Proposta que Foucault realiza em ato ao recusar ser o porta-voz dos revoltosos, ou indicar caminho às suas ações, por exemplo, rompendo com certa tradição sobre o papel do filósofo na sociedade, passando a desempenhar um papel mais analítico, percebendo e pensando sobre a emergência de novas subjetividades que rompiam os limites do pensável e colocavam em xeque, resistindo ou impedindo, os próprios jogos de poder. São as formas inventadas de resistência que o interessam, capazes de ir contra um poder que repousa na “contingência e na fragilidade de uma história" (FOUCAULT, 2007, p. 275), na maneira como um indivíduo aceita o fato de que nenhum poder é incontestável e suspende toda e qualquer verdade que emana do mesmo, criando um escape em relação à história da qual faz parte. Dessa maneira, sua crítica só é válida na medida em que multiplicaria, ou permitiria inventar, novos sinais de existência dentro do campo político (FOUCAULT, 2008). 


\section{Da inexistência cotidiana à resistência ética}

Podemos dizer que vivemos em um espaço de inexistência concebendo este como um espaço em que a vida jaz sem potência, ou cercada de limites. Ao utilizar a crítica como uma forma de tensionar esse espaço, nossa relação com o passado e com o futuro através de uma remodelação do meu eu no presente, é que um novo espaço de experiência se abre e novas práticas de libertação emergem - o "entre", um campo imanente. As formas de existência que pré-configuram nosso ser, as inexistências, são quebradas em nome de um novo existir mais intensivo e potente - a vida, neste quadro, cercada de risco por tal quebra, transforma-se em resistência.

Podemos constatar que a revolta de Foucault se difere muito das visões que estamos acostumados. Não se trata de uma liberação política dos indivíduos, mas de uma outra forma de revolta. Voltemos ao texto É inútil revoltar-se? para melhor compreendê-la:

Chegou a época da "revolução". Há dois séculos ela se projetou sobre a história, organizou nossa percepção do tempo, polarizou as esperanças. Realizou um gigantesco esforço para aclimatar a insurreição no interior de uma história racional e controlável. Ela the deu legitimidade, escolheu suas boas ou más formas, definiu as leis do seu desenvolvimento, estabeleceu suas condições prévias, objetivos e maneiras de se acabar. Chegou-se mesmo a definir a profissão do revolucionário (FOUCAULT, 2010c, p.78).

A história quando mal utilizada pode acabar com a força plástica da vida, como mostra o trecho em questão: a revolução que se projetou no espaço de experiência não só instituiu o Antigo Regime como uma má forma de governo, mas colocou um novo horizonte de expectativa que polarizou as esperanças e instituiu uma nova cadeia de razão aos homens que dali por diante a vivenciariam. Neste horizonte cabia aceitar sem protestos o que se colocava: o progresso do homem à luz de certa razão, ou bater de frente com a mesma, mas sem sequer arranhar seu eixo principal - a ideia de progresso. Daí esta profissão de revolucionário de que nos fala Foucault, estes que pregam o progresso da humanidade, contra a sociedade vigente, mas dentro da mesma cadeia de razão que fundamentou o antigo regime social.

A revolução apareceria como um mero abalo dentro de uma história racional e controlável, uma vez que o homem buscaria somente submeter-se a um imperativo externo qualquer, visto como necessário, e a liberdade não 
passaria de uma obrigação. A história, na leitura de Foucault, impõe formas de controle, delega papéis, engendra um jogo de representações por meio das formas de vida impostas. Pensar a história de forma evolutiva, como os revolucionários russos a pensaram, por exemplo, nada mais é do que seguir as linhas do sistema de pensamento implementadas pela Revolução Francesa². Legitima-se uma continuidade determinista dos desdobramentos do mundo, cujo maior imperativo se apóia no progresso da racionalidade política ocidental. A história, portanto, acaba por calar o que um indivíduo tem de mais forte e produz inexistências - na medida em que narrativas outras que o indivíduo poderia desempenhar em sua vida não estão contidas nessa metanarrativa do progresso.

Não se trata aqui, cabe ressaltar, de uma dominação violenta - uma lobotomização sem precedentes -, mas sim de uma forma de governo que oferece uma espécie de liberdade regulada, da qual poucos indivíduos se dão conta. Nossa vida, nosso jeito de ser e de se portar, portanto, é moldada dentro de um certo sistema de pensamento, no qual aceitamos certos limites sem nos darmos conta. Delimitações que podemos perceber através de simples estudos genealógicos, como os elaborados por Foucault, nos quais até mesmo os atos cotidianos são colocados em dúvida. Dessa forma, temos que ter em mente que:

Esta forma de poder aplica-se à vida cotidiana imediata que categoriza o indivíduo, marca-o com sua própria individualidade, ligao à sua própria identidade, impõe-lhe uma lei de verdade, que devemos reconhecer e que os outros têm que reconhecer nele. É uma forma de poder que faz dos indivíduos sujeitos (FOUCAULT, 2010b, p. 235).

Assumir uma atitude crítica, remodelar-se diante do poder através de uma nova forma de pensar, é a forma pela qual Foucault pensa livrar-se dos imperativos que modelam nosso modo de agir e pensar. Retomar o projeto de uma filosofia crítica é buscar desmascarar os "discursos de tragédia" que encobrem a "trama de nossa vida cotidiana" (FOUCAULT, 2010, p. 235) e nos submete aos jogos de poder sem que o percebamos.

\footnotetext{
${ }^{2}$ O que não significa que a liberação seja de todo negativa, Foucault nos diz: "a liberação é às vezes a condição política ou histórica para uma prática da liberdade. (...) A relação abre um campo para novas relações de poder, que devem ser controladas por práticas de liberdade" (FOUCAULT. 2010d. p.267).
} 
A liberdade, nesse contexto, entra em confronto com as condições estipuladas pelo jogo de poder vigente em uma dada sociedade. Nada de liberdade total, como prometido pela revolução, mas movimento e invenção constante de lutas e práticas. A revolta surge como um exercício sobre si proporcionado pela crítica que leva à criação de um novo modo de ser, um modo configurado por um outro espaço de pensamento. A ética, em Foucault, nada mais é do que a prática refletida da liberdade, assumindo exatamente por isto um caráter político.

A liberdade é, em si mesma, política. Além disso, ela também tem um modelo político, uma vez que ser livre significa não ser escravo de si mesmo nem dos seus apetites, o que implica estabelecer consigo mesmo uma certa relação de domínio, de controle, chamada de arché - poder, comando. (FOUCAULT, 2010d, p.269)

Na problematização buscada por tal crítica acabamos por compreender nossa ontologia, ou seja, como: “constituímos a nós mesmos em um local e em uma época, usando materiais que têm uma organização historicamente formada" (HACKING, 2009, p.15). Por mais paradoxal que possa parecer, é só estando dentro do jogo que podemos recusar ou resistir ao jogo sem sermos subjugados pelo próprio. Somente na materialidade do campo discursivo que circulamos é que podemos resistir, a partir do momento em que percebemos a contingência inerente ao jogo estabelecido pelas e nas relações de poder. É como filósofo analítico que se utiliza da crítica que Foucault concebe esta outra experiência, para que a mesma não seja calada é necessário colocar-se dentro do jogo como governado, criando resistência e desestabilizando-o. Tal mergulho na existência combate também a representação, na medida em que o filósofo entra em cena com a sua própria vida, com sua presença física e não apenas discursiva.

Atitude que, interessante notar, parte de um único indivíduo, mas acaba por tensionar o todo social e alcançando muitos, uma vez que todos são iguais dentro do jogo: governados! Para ilustrar este aspecto tomemos outro texto de Foucault, este de 1981, escrito e interpretado pelo autor em Genebra após o anúncio da Criaşão do Comitê Internacional contra Pirataria, chamado O direito dos bomens face aos governos. Nele, Foucault reconhece que todos ali, incluindo ele, não passam de "homens despojados, que não têm de outro título a falar, e a falar juntos, senão de uma certa dificuldade comum para suportar o que se 
passa" (2010e, p.369). Ora, é desta situação insuportável, como homem governado, que Foucault pode colocar sua crítica da razão política em ação e estabelecer três diretrizes para revolta. Enunciemos, portanto, as principais consequências dessas diretrizes.

Em primeiro lugar, Foucault reconhece que, sob o jugo do direito e da cidadania, todos somos governados, daí não haver distinção entre o filósofo, por exemplo, e o cidadão mais comum já que ambos participam do mesmo jogo. Além disso, como cidadãos governados, que sofrem abusos e se calam, cabe aos representantes do direito tomar a fala e colocar-se diante do poder em nome destes, como regra inerente ao próprio jogo. Por fim, aos indivíduos, que já contam com essa representação, cabe não apenas esperar passivamente o resultado desta divisão de tarefas apontada anteriormente - os que são oprimidos e se calam, os que falam em nome dos oprimidos e os que agem em prol dos oprimidos -, mas recusar os papéis impostos por este direito e, recusando toda e qualquer forma de representação, revoltar-se para tomar a realidade novamente em suas mãos.

Apresentamos este resumo, mas procuremos ressaltar esse terceiro tópico, a incitação à revolta proposta. Trata-se não da revolta muda dos que são governados e aceitam o papel imposto ou a delegação de papéis por outros revoltosos, mas a revolta daqueles que põem contra o jogo sua própria vida e, contra esses, nos lembra Foucault: "não se impõe a lei a quem arrisca sua vida diante de um poder" (FOUCAULT, 2010c. p.80). Recusar veementemente o papel imposto a cada um como governado, recusar a teatralização da vida infligida pelas formas de vida em prol da potência da existência e assumir uma outra atitude diante do mundo.

O sujeito acaba sendo o ponto mais importante em todo este processo, ele é o ponto radiador da revolta, daí toda a atenção de Foucault acabar recaindo sobre essa figura nesse momento de sua obra. O campo de luta é primeiramente ético, e só através de uma mudança ética é que se torna possível o tensionar do campo político, mas como isto ocorre? Ecos que tomam corpo em um texto de 1980, Omnes et Singulatim: uma crítica da razão política, no qual é passível constatar que Foucault retoma muitos dos pontos aqui já tratados e analisa as técnicas de poder voltadas aos indivíduos e sua relação com o Estado, de modo a compreender o problema político por excelência, o 
governo da cidade e dos cidadãos, e sua relação com o governo dos indivíduos, o governo do rebanho pelo pastor - o problema pastoral que concerne à vida dos indivíduos. O caráter demoníaco do Estado moderno, de acordo com Foucault, combinou estes dois grandes jogos, o da cidade e do cidadão e do pastor e do rebanho, e cabia ao filósofo denunciar os abusos cometidos em nome da junção destes jogos, justamente a tarefa que Foucault vinha buscando com sua crítica da razão política.

Em Omnes et Singulatim, Foucault lança mais alguns postulados que devem the servir de base e que podem nos ajudar a aprofundar tal questão, a saber: 1) Toda liberdade conduz ao governo; 2) Há uma racionalidade imposta a todas relações que envolvam o governo dos homens sobre outros homens; 3 ) existe a necessidade de apontar os problemas inerentes a tal racionalidade; e 4) a liberação só poderá surgir através do ataque às raízes da própria racionalidade política. Se somos governados, se algum poder é exercido sobre nós, isto se deve pelo fato de sermos livres - Foucault nos lembra que não há relação de poder sem liberdade -, e implica na existência de uma certa racionalidade que nos liga uns aos outros e nos submete a outrem; pois bem, cabe ao filósofo apontar quando esta racionalidade produz certos abusos de poder e, o que nos interessa, cabe buscarmos a liberação através do ataque às suas próprias raízes. Quais seriam as raízes da racionalidade política?

Para Foucault, o indivíduo não é formado abaixo ou ao lado do Estado e suas políticas disciplinadoras, mas sim dentro dele e ao mesmo tempo. O poder estatal não ignora os indivíduos, não é apenas uma forma de poder totalizadora, mas é também uma forma individualizante, na medida em que através de diversas tecnologias, submete os indivíduos a modelos muitos específicos de viver. As formas que vivemos, a maneira por meio da qual nos concebemos como sujeitos, bem como o poder ao qual obedecemos, fazem parte, portanto, da mesma racionalidade política; atacar uma é atacar a outra. Remodelar-se eticamente é, também, uma forma de atacar à raiz da racionalidade política que nos formou.

A crítica da razão política buscada por Foucault exige esta reformulação ética, portanto, mas porque só após tantos séculos a ética volta a figurar ao lado da questão política? Foucault nos lembra que:

Durante séculos, fomos convencidos de que entre nossa ética, nossa 
ética pessoal, nossa vida de todo dia e as grandes estruturas políticas, sociais e econômicas, havia relações analíticas, e que nós nada poderíamos mudar, por exemplo, de nossa vida sexual ou de nossa vida familiar sem arruinar a nossa economia, a nossa democracia etc. Creio que devemos nos libertar dessa ideia de um elo analítico ou necessário entre a ética e as outras estruturas sociais ou econômicas ou políticas (FOUCAULT, 2010f, p. 306).

Podemos dizer que se há recusa em mudarmos eticamente, esta se deve pelo fato de acreditarmos que qualquer mudança em nosso modo de existir poderia prejudicar o todo e romperia num caos total. Ironicamente, ao mesmo tempo nos concebemos como sujeitos livres e autônomos. Isto ocorre através do que Foucault (2010f) denomina de Tecnologia política dos indivíduos, capaz de capturar a vida dos sujeitos nas micro-malhas do poder através da imposição de regras de condutas universais e por nos levar a concebermos dentro das cadeias da razão histórica.

A liberação tradicional não escaparia desta lógica formal que nos foi imposta através da racionalidade histórica da modernidade, por isto a necessidade de modificar-se, buscar uma outra experiência do pensamento e uma outra atitude.

Impressiona em Foucault o quanto uma simples atitude é capaz de desestabilizar o todo, mas atingir esta atitude é mais difícil do que parece. Há o hábito, a variação simples do pensamento, etc., que acabam por criar empecilhos para uma real experiência do pensamento. Como quebrar esses limites cotidianos que nos cegam sem cair em outra cela dentro da cadeia da razão? Através de uma crítica infinita, um movimento que nunca se esgotaria, mas uma crítica infinita não poderia se transformar num hábito incapaz de quebrar o cotidiano? Como agir neste campo? Para respondermos tais questões, retomamos as últimas pesquisas feitas pelo filósofo francês e nos deparamos com o conceito de parrhesia, ou algo como a coragem do dizerverdadeiro.

\section{Crítica da razão política e parrhesia}

Foucault nos diz que: "O que caracteriza o enunciado parresiástico é que, justamente, fora do estatuto e de tudo o que podemos codificar e determinar a situação, o parrhesiasta é aquele que faz valer sua própria liberdade de indivíduo que fala" (FOUCAULT, 2010g, p.63). Se a crítica é a 
estratégia de jogo utilizada pelo filósofo, colocar-se como governado é a aceitação do jogo e suas regras, a parrhesia é o lançar de dados tensionando o campo da experiência e desestabilizando o jogo teatral em suas próprias regras.

Contra o papel teatral imposto a cada um de nós, este estatuto que nos é imposto e ao qual só nos cabe reclamar, o parrhesiasta é aquele que faz valer sua liberdade de indivíduo que fala, levando-o para além do simples estatuto de cidadão. Tal ato, por sua vez, não é gratuito, uma vez que a parrhesia sempre inclui alguma forma de risco àquele que fala.

O parrhesiasta é aquele que, aceitando o papel de governado, toma sua vida em suas próprias mãos e faz com que toda a artificialidade deste aparato de vigilância que recai sobre si venha abaixo por trazer à tona os abusos do poder. A partir da ação intensiva, que se insere em atividade no corpo social de modo limítrofe, na medida em que o dizer verdadeiro coloca a vida do parrhesiasta em perigo, pode-se apontar essa radicalidade criadora. Ora, temos aqui, precisamente, o homem que Foucault parecia buscar em sua crítica da razão política.

O dizer verdadeiro é indissociável do jogo político: "A parrhesia é algo cujo lugar é definido pela política. Mas a parrhesia, o dizer-a-verdade do político é aquilo que vai assegurando o jogo conveniente da política" (2010g, p.148). Apesar de a parrhesia ser um campo formulado pela própria política, ela a escapa, permitindo algo inusitado, ao mesmo tempo em que a regula, estabelece seus limites, e a lança em novos parâmetros impedindo que abuse de seu próprio poder.

Acreditamos que a parrhesia exige uma nova experiência de si, passível de vir à tona somente através daquele longo trabalho crítico que vimos anteriormente. Mas não poderíamos, porém, conceber a fala parresiástica como mera retórica e uma outra forma de governo? Convém lembrar que a parrhesia não pertence a um demagogo ou a um retórico, uma vez que, como coloca Fréderic Gros, trata-se de:

uma fala engajada: parrhesia supõe uma adesão do falante a seu enunciado; trata-se de enunciar uma verdade que constitui uma convicção pessoal, ao passo que o problema do retórico não é acreditar, mas fazer acreditar (passagem da convicção à persuasão). Por fim, uma fala perigosa: a parrhesia supõe coragem, porque se trata quase sempre de uma verdade que pode ferir o outro e que assume o risco de uma reação negativa da parte dele, ao passo que a retórica, bem o sabemos, busca bajular o outro, torná-lo dependente de um 
discurso mentiroso (Gros, 2004, p.157).

O parrhesiasta é aquele que, através de um duro trabalho de si sobre si mesmo, consegue aliar seu éthos a uma determinada prática de liberdade, ao uso refletido desta liberdade e da verdade que ela traz consigo; só assim este éthos será reconhecido e admirado pelos demais. A verdade é aplicada à própria existência. O cuidado de si que leva a parrhesia é condição sine qua non para a constituição do sujeito que governa, sem com isso levar ao abuso de poder sobre outrem.

\section{Considerações finais}

O parrhesiasta, se o concebermos dentro do projeto de crítica à razão política almejado por Foucault, é aquele que se torna capaz de perceber-se ontologicamente, bem como os limites de sua capacidade de ação. Se é possível exigir dos governos uma certa verdade em relação aos projetos finais, às escolhas gerais de sua tática, a um certo número de pontos particulares de seu programa, o mais indicado para realizar estas exigências é aquele que se utiliza da parrhesia, a ponto de a interpelação tornar-se um dever do parrhesiasta, mas não por este portar a verdade - como se houvesse uma verdade absoluta, transcendental - e sim pelo fato de que também é um governado.

Por que o parrhesiasta escapa desta teatralização do cotidiano? Talvez devido ao fato de que ele acaba não se submetendo aos regimes de verdade impostos pela razão política dominante, regimes que não implicam somente na aceitação do governo, "eu obedeço", mas também na aceitação de uma certa essência, “eis aquilo que sou, eu que obedeço...” (FOUCAULT, 2010c, p. 78); ao contrário, o parrhesiasta é aquele que cria seus próprios regimes de verdade e recusa as regras de conduta universal em nome de sua própria verdade, cuja existência e resistência são ligadas ao caráter operatório e reflexivo da parrbesia. Ao reconhecer-se como portador de um universo, ao praticar o cuidado de si, o parrhesiasta acaba encontrando uma outra forma de estar no mundo.

A existência bela do parrhesiasta é buscada através do reconhecimento de um certo número de regras, de estilos, de convenções que podemos encontrar no meio cultural, neste meio que o parrhesiasta busca afirmar sua liberdade e dar à sua própria vida uma certa forma na qual era possível se reconhecer, ser reconhecido pelos outros e na qual a própria posteridade pode 
encontrar um exemplo. Uma escolha pessoal, pautada em seus próprios valores estéticos, capaz de fazer com que o sujeito tome sua vida como uma obra de arte a ser lançada e reconhecida em um meio mais amplo, isto é, a própria crítica da razão política.

$\mathrm{Na}$ medida em que esta existência transcende ética-esteticamente o papel que lhe é imposto, na medida em que busca jogar contra o poder a partir do dizer verdadeiro, mesmo que isto custe sua existência, é que podemos dizer que a forma que pensamos a política e a nós mesmos é tensionada e, deste encontro, buscamos potencializar nossa vida, res(ex)istir através do ato de "recusar aquilo que somos" (FOUCAULT, 2010c, p. 79).

\section{Referências bibliográficas}

. "A ética do cuidado de si como prática de liberdade". In: FOUCAULT, Michel. Ditos \& Escritos V: Ética, sexualidade, politica. Rio de Janeiro: Forense Universitária, 2010d. p.264-287.

. "A filosofia analítica do poder". In: FOUCAULT, Michel.

Ditos es Escritos V: Ética, sexualidade, política. Rio de Janeiro: Forense Universitária, 2010a. p.37-55.

"Do direito dos homens face aos governos". In:

FOUCAULT, Michel. Ditos \& Escritos VI: Repensar a política. Rio de Janeiro: Forense Universitária, 2010e. p.369-370.

. "Do governo dos vivos". In: Revista Verve, Nu-Sol/PUC-

SP, no 12.2007 , p. $270-297$.

."É inútil revoltar-se?”. In: FOUCAULT, Michel. Ditos \&

Escritos V: Ética, sexualidade, política. Rio de Janeiro: Forense Universitária, 2010c.p.77-81.

"Michel Foucault entrevistado por Hubert L. Dreyfus e

Paul Rabinow". In: DREYFUS, H.L., RABINOW, P. Michel Foucault: uma 
Perspectiva Filosófica, vol. 45, n. 1, 2018

trajetória filosófica: para além do estruturalismo e da hermenêutica. Rio de Janeiro: Forense Universitária, 2010f. p.296-327.

. O Governo de Si e dos Outros. São Paulo: Martins Fontes,

2010g.

. “O que são as luzes?”. In: FOUCAULT, Michel. Ditos \&

Escritos II: Arqueologia das Ciências e História dos sistemas de pensamento. Rio de Janeiro: Forense Universitária, 2008. p.335-351.

. "O sujeito e o poder". In: DREYFUS, H.L., RABINOW,

P. Michel Foucault: uma trajetória filosófica: para além do estruturalismo e da bermenêutica.

Rio de Janeiro: Forense Universitária, 2010b. p.273-295.

. “Omnes et Singulatim': uma crítica da razão política”. In:

FOUCAULT, Michel. Ditos \& Escritos IV : Estratégia, poder-saber. Rio de Janeiro:

Forense Universitária, 2010d. p.355-386.

GROS, Frédric. "A parrhesia em Foucault (1982-1984)”. In: GROS, Frédric (org.). Foucault: a coragem da verdade. São Paulo: Parábola Editorial, 2004. p.155166.

HACKING, Ian. Ontologia Histórica. Rio Grande do Sul: Unisinos, 2009.

KANT, Immanuel. Crítica da Razão Pura. Lisboa: Calouste Gulbekian. 2011.

O que é o esclarecimento?. Rio de Janeiro: Via Verita, 2013. 